\title{
KULTURA ISHRANE U VERSKOM TURIZMU
}

\author{
Ivan D. Kosta \\ Član alumni asocijacije \\ Univerziteta Singidunum, \\ Beograd, Srbija
}

\section{Rezime:}

Rad ima za cilj da otvori pitanje postojanja potrebe multikulturalnog pristupa hrani u oblasti potreba verskog turizma kao i da otvori sagledavanje potreba ali i ukaže na nedostatke kada je hrana kao kulturno nasleđe nematerijalnog tipa u pitanju. Srbija je zemlja poznata po gostoprimstvu i bogatoj gastronomskoj ponudi. Njena potreba je i uspešno ostvarivanje na polju verskog turizma. Bogatstvo materijalnog i nematerijalnog nasleđa, koje može da daruje svim turistima koji je posete, glavni je njen adut u vremenu koje dolazi.

Ključne reči:

halal, košer, verski turizam, verski lideri, kultura

Tradicija, predanja, istorija i savremeni tokovi razvoja turizma kao globalne pojave okupljeni oko verskih lidera, stručnjaka različitih profila i razlike koje nas naizgled razdvajaju i spajaju. Duhovni ili religiozni turizam, hodočasnik, vernik, ateista ili pak verski turista? Gde su tačke koje sve ove teme spajaju, a gde one koje razdvajaju? Halal standardi ili čar "Salvatore's Legacy",-a? Košer strogoća ili mistika poisson Saint Pierre i coquilles Caint Jacques? Da li Srbija prepoznaje resurse koje ima? Verski turizam sa svim svojim različitostima koje proističu iz nacionalnih, tradicionalnih i verskih segmenata predstavlja čvrst potencijal.

\section{VERSKI TURIZAM DANAS}

Turistički trendovi danas i predviđanja za budućnost pokazuju koliko je turizam do sada napredovao i koliko prostora ima za širenje bez jasno postavljenih granica. Sve je više učesnika u turizmu i taj broj će nastaviti da raste. Duhovni turizam ima za cilj da istraži elemente života koji su izvan nečije percepcije i pomogne da se uspostavi ravnoteža telo, um i duh. Gde vode putevi verskog turizma? Da li nas različitosti spajaju? Koliko je važna tradicija u ishrani i različite religije? Posetioci pokušavaju da razviju svoju duhovnost, ili otkrivanje duhovnost drugih. Turizam i hodočašće su usko povezani i u modernoj masovnoj 
ekspanziji hodočašća ponašanje hodočasnika se često ne razlikuje od običnog turiste Jaka konkurencija koja vlada na turističkom tržištu stavlja ugostitelje i hotelijere u poziciju gde ona moraju svoju uslugu da diferenciraju i time postignu konkurentsku prednost. Za diferenciranje proizvoda potrebno je, najpre, shvatiti koji je ciljni segment uslužnog preduzeća i zatim analizirati mogućnosti i resurse preduzeća da ponudi i isporuči uslugu koju je namenilo tom segmentu. Verski turizam ima izrazitu potrebu za ovakvim delovanjem. Nieminen (2012) u svom radu o verskom turizmu ističe da postoje različite kategorije pod pojmom verskog turizma. „Hodočašća i misionarska putovanja su dva najveća oblika verskog turizma... Hrišćanska hodočašća mogu biti potkrepljena nekim od sledećih motiva: istraživanje korena hrišćanske vere, otkrivanje doprinosa hrišćanstva Zapadnoj civilizaciji, traženje inspiracije iz primera nekog velikog čoveka, ženu ili svetitelja hrišćanstva, učenje hrišćana u prošlosti, potraga za duhovnim ili emocionalnim isceljenjenjem ili kombinovanje fizičkog odmora sa hodočašćem, kao na primer Santiago de Compostela ruta. Evropa nudi skoro dvadeset vekova hrišćanskog nasleđa, istorije i vera, uključujući korene mnogih hrišćanskih denominacija (Nieminen, 2012). Termin „duhovni turizam” je u velikoj meri nepoznanica i u akademskoj literaturi i turističkim izdanjima, ali ipak više ljudi poseti Meku, Vatikan i Vitlejem/Jerusalim godišnje nego što prisustvuje Svetskom prvenstva, na primer. Neophodno je razviti marketing duhovnog turizma kako bi se ova tema i njen razvoj u budućnosti intenzivirao, navode Haq i Jackson (2006). Ishrana turista na destinaciji je suštinska i jedinstvena komponenta ukupnog turističkog proizvoda i impuls tog savremenog nutritivnog koncepta je ogroman. Navike u ishrani određene verskim uverenjima turista, tokom njihovog putovanja i boravka na odabranoj destinaciji postaju važan segment u turizmu (Son \& Xu, 2013). Mnoge religije imaju pravila u ishrani koja se razlikuju u tome šta, kako i kada treba jesti ili koje namirnice treba izbegavati.

\section{JEDINSTVO U RAZLIČITOSTIMA}

Kada govorimo o specifičnosti prehrembenih navika i konzumiranja hrane kod Jevreja odmah na samom početku treba istaći da oni koriste hranu koja je isključivo košer. Košer kod Jevreja znači da je hrana čista tj. dozvoljena za upotrebu -korišćenje. Postoje četiri kateogorije hrane kod Jevreja: proizvodi koji nisu košer, koji uključuju mešavinu mesa i mlečnih proizvoda, kao i mešavinu ribe i mesa, zatim meso, mlečni proizvodi kao i takozvani neutralni proizvodi. Da bi određeni mesni proizvodi i samo meso bili košer neophodno je životinju na poseban ritualan način, unapred određen zaklati. Tako na primer životinje koje žvaću hranu i iz posebnih posuda se hrane (teletina, ovčetina) mogu se nazvati košer hrana i spadaju u vrste mesa koje su dozvoljena. Osobe koje vrše obred ubijanja na specijalan način koji ne zadaje bol naziva se šočet. Da bi meso bilo košer uklanjaju se krvni sudovi kao i šijatički nerv, pristupa se odstranjivanju iznutrica, krvi i ostalih nerava, kao i ispitivanju na bolesti. Pluća moraju biti čista, zdrava. Ovo je poznato kao košerovanje mesa. Ono se obavlja u pet koraka (Kalenjuk, 2016): meso se natapa (u roku od 72 sata od klanja) u mlakoj vodi 30 minuta; cedi se na kosoj, rupičastoj površini tako da krv može lako da iscuri; meso se pokriva košer solju najmanje sat vremena; so se ispira iz mesa; konačno meso se iznova ispira kako bi se osiguralo da je sva krv i so uklonjena. Jevreji u svojoj bogatoj tradiciji koriste i živinsko meso, ali se ono nikako ne sme mešati sa mlečnim proizvodima. Podrazumeva se da se klanje živine takođe obavlja po košer standardima i može ga obaviti isključivo šočet. Oni koriste kokošije, pačeće, guščije i ćureće meso, dok ribe koje imaju krljušt i peraja spadaju takođe u košer, te tako na primer mogu jesti meso lososa, tune, bele ribe, dok druge vrste morskih riba kao i sve vrse ljuskara, kraba, školjki, jastoga, hobotnica, rakova nisu košer. Zabranjuje se korišćenje soma i šarana kao vrste riba, jer nisu košer. Meso i mlečni proizvodi se nikada ne jedu zajedno i neophodno je da prođe sat vremena kako bi se nakom mlečnih proizvoda jelo meso, dok posle korišćenja mesa treba minimum šest sati pauze da bi se mogli konzumirati mlečni proizvodi. Voće i sve vrste povrća, kao i zrnasto povrće su takođe košer. Mlečni proizvodi moraju biti napravljeni isključivo od životinja koje su košer uz poštovanje jevrejskih zakona.

Po islamu, ishrana se smatra pitanjem bogosluženja. Od muslimana se očekuje da jedu radi opstanka i dobrog zdravlja; samopovlađivanje nije dozvoljeno. Muslimanima se savetuje da ne jedu više od dve trećine svog kapaciteta i deljenje hrane se preporučuje. Hrana se nikada ne baca, ne propada i ne tretira sa nepoštovanjem. Ruke i usta se peru pre i posle obroka. Ako se ne koristi pribor za jelo, onda se samo koristi desna ruka a leva se smatra nečistom (Kalenjuk, 2016). Kod muslimana postoji niz pravila vezanih za ishranu. Post se smatra prilikom za zasluživanje Alahovog odobrenja, oprost učinjenih grehova i razumevanje i poistovećivanje sa 
patnjama siromašnih. Za vreme Ramazana (deveti mesec u islamskom kalendaru u kom je počela objava Kurana) islamskim vernicima je od zore do zalaska sunca zabranjeno konzumiranje bilo kakve hrane, pića (uključujući i vodu), polnih odnosa i pušenje cigareta (Burke \& King, 2012). Halal je arapski termin.U svom izvornom značenju označava da je nešto dozvoljeno, zakonom odobreno. Šerijatski zakon strogo definiše način ishrane i svaki musliman širom sveta ga se pridržava. Strogo se zabranjuje svinjsko meso kao i proizvodi koji je sadrže, takođe meso obolelih životinja ili životinja koje nisu zaklane po strogim normama halala u ime Alaha, zatim proizvodi koji sadrže krv, životinje mesojedi, ptice grabljivice, aditivi i emulgatori, želatin i alkohol su zabranjeni (haram). Zabranjene su sve svinje, četvoronožne životine koje love plen ustima, ptice grabljivice koje grabe plen svojim kandžama i svi nus proizvodi ovih životinja, poput svinjskog želatina ili enzima koji se koriste u proizvodnji sira. Voće, povrće i žitarice su dozvoljene ako se ne kontaminiraju zabranjenom hranom. Ispijanje stimulansa, kao što su kafa i čaj se ne podržava, kao i pušenje; međutim ove zabrane se praktikuju samo od strane najposvećenijih muslimana.

Pravoslavci za vreme posta ne konzumiraju meso i sve životinjske proizvode (mleko, jaja, maslac i sir) . Katolici poste na nešto blaži način i to tokom korizme, zatim 40 dana pred Uskrs, zadnji petak u Adventu, Čistu sredu i Veliki petak. Sat pre pričešća ne jedu. Protestanti retko poste. Posebne prehrambene navike su karakteristične za dve protestantske struje: mormone i adventiste. Mormoni izbegavaju preteranu konzumaciju alkoholnih pića, kafe i čaja (kao i sve što sadrži kofein), a adventisti izbegavaju prejedanje. Veliki broj njih su lakto-vegetarijanci (Gagić et al., 2017).

Dakle, analizirajući način ishrane osnovnih monoteističkih religija u svetu, jasno je da se može doći do zaključka da je neophodna dobra edukacija ljudi koji će se baviti obezbeđivanjem, pripremom i serviranjem hrane za poklonike, religioznog ili turistu u okviru verskog turizma. Naizgled bezazlena tema može postati prepreka ali i kamen spoticanja u pravom implementiranju verskog turizma u našu svakodnevnicu. Verski turista nije običan gost. On sa sobom nosi svoju tradiciju, duboke korene koji su zasnovani na njegovim verskim ubeđenjima i svetim knjigama, Tori, Kuranu, Svetom pismu. Na današnjem veoma konkurentnom tržištu veoma je teško zadovoljiti potrebe sve zahtevnijih gostiju, a uvažavanje njihove verske pripadnosti se vidi kao dobar način za privlačenje onih gostiju koji poštuju norme ponašanja koje prepisuje njihova religija. Očigledno je da u svetu košer i halal standardi predstavljaju jasne primere ekonomske stabilnosti velikih kompanija dok je taj trend kod nas u neznatnom, nedovoljnom razvoju. Saradnja i spoznaja jednih drugih temelj je uspešnog delovanja u svetu zahvaćenim ratovima, nasiljem, verskim fanatizmom, terorizmom. Propisi za Jevreje, hrišćane i muslimane imaju mnogobrojne sličnosti u zabrani određenih životinja (kao što su svinje), zabrana krvi, uloga gladovanja i dobrobit životinja. Ovi spisi zahtevaju najviši stepen poštovanja za život životinja (uticaj uzgoja životinja i procesa klanja), preferencija sastojaka na biljnoj bazi u poređenju sa sastojcima mesnih i zamena svinjskog mesa od goveđim. Ispunjavanje tih verske principa je važno za poljoprivredu i prehrambenu industriju, jer se baš njih pridržava više od polovine svetske populacije (61,3 odsto do 2050. godine) (Tieman \& Hassan, 2015). Digitalno okruženje nedvosmisleno nam ide kao saputnik u ovoj priči. Svedoci smo toga da je "duhovno buđenje” ljudi u toku, na šta ukazuje i razvoj verskog turizma koji zbog svojih specifičnosti i karakteristika zahteva da se više sprovode odgovarajuća istraživanja u cilju boljeg shvatanja njegovih dimenzija, oblika, upravljanja i uticaja na spomenike. Takođe, njegova precizna definicija omogućava sprovođenje konkretnih koncepata i mera. Važno je pomenuti da se planiranje i promotivna kampanja (i klasična i digitalna) moraju sprovoditi sinhronizovano sa razvojem turističke industrije, nevezano da li se radi o klasičnim hodočašćima ili verskim putovanjima. U vezi sa tim, da bi se uspostavila adekvatna digitalna promocija verskog turizma, neophodno je stvaranje saradničke mreže između turističke destinacije (odnosno lokaliteta), turističkih profesionalaca, državnih organa, ali i članova akademske zajednice koji će zajedničkim delovanjem doprineti da se versko putovanje približi turistima, ali i da se izbegnu stereotipi, podsticanje na rasizam, ksenofobiju ili ekstremni nacionalizam i terorizam. Svakako neizostavni deo pripreme digitalne kampanje u verskom turizmu čini ugledanje na dobre primere iz prakse u oblasti verskog turizma jer nude odgovarajuće smernice u postavljanju i razvoju navedenih sadržaja. Takođe, u ovom slučaju važna je i primena Opšteg etičkog kodeksa u turizmu (GCET) pod čijim načelima treba razvijati ovu delatnost (Živković et al.,2017). Ti izazovi koji se pred nas postavljaju u vremenu u kome živimo i delamo moraju da budu izazovi u kojima naše povezivanje neće imati samo ekonomski smisao već smisao dat kroz autentičnost religijskog učenja svakog od nas ponaosob bez obzira na različitosti. Niko ne očekuje da različitosti budu poništene, da razmimoilaženja budu izbrisana. Naprotiv, potrebno je samo da se ljubavlju međusobnih odnosa i saradnje 
upoznamo bolje i da grupisani počnemo delati šireći dobro oko nas. No, ostaje otvoreno pitanje koliko se po pitanju samog verskog turizma duhovni lideri mogu sjediniti u istim ili bar sličnim mišljenjima.

No, u stvarnosti, u senci sukoba verskih lidera na relaciji Moškovska patrijaršija - Carigradska patrijaršija- nepriznata Ukrajnska crkva ova tema bledi i ostavlja nas nedorečene kada je saradnja u pitanju. Uređenje verskog turizma, međusobno povezivanje i saradnja verskim liderima daće snagu i moć da na adekvatan način odgovore izazovima koje vreme pred nas postavlja zahtevajući da verski turizam zauzme svoje pravo mesto i od neiskorišćenog resursa postane resurs zajedništva, spajanja, saživota, tolerancije i bezuslovne saradnje. Otvaranjem vrata sinagoga, džamija, manastira mi otvaramo vrata spoznaje jednih drugih, postavljamo temelje saradnje i ostvarivanju zajedničkih interesa i ekonomskih i duhovnih. On predstavnike religija može da spoji dajući delatni primer vernicima da takav primer sleduju i u svojim životima. Tada ćemo biti kadri da čuvši jedni druge, uvidimo da pred nama leži zlatni rudnik duhovne i materijalne dobrobiti (Kosta, 2017). Da se zaključiti da polje verskog turizma jeste plodonosno po pitanju saradnje verskih zajednica i tradicionalnih crkava. Ono je ujedno i krajnja neminovnost ukoliko se pitanje verskog turizma shvata kao ozbiljan projekat izlaska na domaće i međunarodno turističko tržište. U prilog navedenog idu i podaci iz našeg okruženja i vremena u kojem živimo gde se organizuju mnogobrojni sastanci, radan tela, radne grupe, komisije, saveti u kojim ravnopravno učestvuju predstavnici tradicionalnih crkava i verskih zajednica Srbije i okruženja. Isto tako, poruke ljubavi, tolerancije i mira odzvanjaju i šalju duboke poruke javnom mnjenju dok istupi negativnih prizvuka i primera dugo ostaju teme medijskih analiza i svakodnevnice. Verski službenici postaju važan faktor dešavanja i neosporni činioci donošenja odluka, direktno ili indirektno, kao i putokazi civilizacijskim tvorevinama vremena u kojem živimo. Neretko i učesnici dnevno-političkih dešavanja. Primeri dobre saradnje i tolerancije, prevazilaženje bremena istorije i prošlih vremena, moraju biti prioriteti duhovnih lidera bez izgovora. Tek tada uspešna inpletacija verskog turizma u Srbiji može imati svoje bogate rezultate.

Stanje u Srbiji nije na zavidnom nivou kada je gastronomska ponuda u skladu sa verskim standardima monoteističkih religija u pitanju. U verskom turizmu Srbije, nophodno je temeljnije zaokruživanje proizvoda i davanje prioriteta razvoju ovog vida turizma, uzimajući u obzir mnoge nedostatke u formiranju ovog turističkog proizvoda Srbije (Kosta, 2018). Najosnovnija potreba verskog turiste je da prilikom posete određenoj destinaciji ima obezbeđene uslove smeštaja i ishrane u skladu sa svojim verskim potrebama i ubeđenjima. Kada pak govorimo o hrićanskim vernicima postavlja se opravdano pitanje na koji način pripremljene, a pre toga čuvane, oni dobijaju u okviru ugostiteljskih usluga objekata u Srbiji? Da li se, na primer, termička obrada mrsne i posne hrane obavlja na jednom istom mestu? Nedostupnost košer i halal sertifikovanih ugostiteljskih objekata, jasno obeleženih proizvoda po ovim standardima u hipermarketima i prodavnicama, needukovanost ugostiteljskih radnika, nemotivisanost samo su neki od uočenih stavki do kojih se došlo. Bez obzira na versku pripadnost, postavlja se neizostavno pitanje za dodatnu analizu da li je verski turista dobrodošao u Srbiju? Ovim pitanjem trebalo bi da se bave stručnjaci različitih oblasti od stručnjaka iz struke, država do pripadnika verskih zajednica i tradicionalnih crkava u Sbiji. Potreba verskih turista je očigledna. Ponuda pak?

\section{ZAKLJUČAK}

Nematerijalno kulturno nasleđe u spoju sa materijalnim, nudi Srbiji mogućnost liderstva u regionu. Bogatstvo tradicije u spoju sa gastronomijom, istorijom i verom predstavljaju izvor ekonomskog prosperiteta i mogućnost značajnih pomaka u oblasti turizma sa posebnim potenciranjem na kulturnom - verskom turizmu. Kulturni turizam u okviru kojeg sagledavamo i verski turizam Srbiji daje mnogobrojne mogućnosti. Svakako da poboljšanje međuljudskih odnosa i tolerancije nikada nije dovoljno te se može sa smelošću zakljućiti da kulturni turizam ima čast da se nazove turizmom mira i međureligijskog dijaloga, tako preko potrebnog današnjem svetu. Iz ove činjenice nesumnjivoje da poštovanje verskih standarda, ubeđenja i potreba verskih turista, hodočasnika jeste kamen temeljac za razvoj verskog turizma. Srbija se nalazi pred izazovom otvaranja vrata svojih bogatih riznica drugim narodima, različitih verskih ubeđenja i nesumnjivo je da taj momenat mora biti uređeniji i da mu se mora dati više pažnje u budućnosti.

Sradanja lokalne zajednice, gradskih i republičkih organa kao i različitih udruženja i organizacija u Srbiji čiji delokrug interesovanja je upravo segment verskog turizma, turizma uopšteno kao i ugostiteljstva, mora biti temeljnija, delotvornija i mnogo ozbiljnija.Verske zajednice i tradicionalne crkve u međusobnoj saradnji 
i dijalogu, u živom i temeljnom odnosu sa predstavnicima državnih organa predstavljaće temelj na kome će verski turizam Srbije biti izgrađivan u budućnosti. Neophodno je započeti dijalog već sada jer neiskorišćenost resursa i slabi rezultati opominju svakodnevno.

\section{LITERATURA}

Burke, L. M., \& King, C. (2012). Ramadan fasting and the goals of sports nutrition around exercise. Journal of sports sciences, 30(Sup.1), S21-S31. doi:10.1080/02640414.2012.680484

Gagić, S., Vuković, A. \& Petrović, M. (2017). Religija i navike u ishrani u hotelijerstvu, In: SITCON 2017: Singidunum International Tourism Conference, 10 September 2017 (pp. 209-214). Beograd: Univerzitet Singidunum. doi:10.15308/Sitcon-2017-209-214

Haq, F., \& Jackson, J. (2006), Exploring consumer segments and typologies of relevance to spiritual tourism, In: Proceedings of the Australia and New Zealand, Academy of Marketing Conference.

Kalenjuk, B. (2016). Nacionalne gastronomije. Novi Sad: Alfagraf.

Kosta, I. (2017). Verski turizam kao osnova za međureligijsko upoznavanje i saradnju, In: SITCON 2017: Singidunum International Tourism Conference, 10 September 2017 (pp. 203-208). Beograd: Univerzitet Singidunum. doi:10.15308/Sitcon-2017-203-208

Kosta, I. (2018). Verski turizam-raskorak izmedu teorije i prakse: master rad. Beograd: Univerzitet Singidunum.

Nieminen, K. (2012). Religious tourism - a Finnish perspective, Masters Thesis of Hospitality Management. Helsinki: Haaga-Helia University of Applied Sciences.

Son, A., \& Xu, H. (2013). Religious food as a tourism attraction: the roles of Buddhist temple food in Western tourist experience. Journal of Heritage Tourism. 8(2-3), 248-258. doi:10.1080/1743873x.2013.767815

Tieman M., F. \& Hassan F. Hj. (2015) Convergence of food systems: Kosher, Christian and Halal. British Food Journal, 117(9), 2313-2327. doi:10.1108/BFJ-02-2015-0058

Živković, R., Brdar, I., Gajić, J. \& Stanković, J. (2017.), Digitalna promocija verskog turizma, In: SITCON 2017: Singidunum International Tourism Conference, 10 September 2017 (pp. 132-139). Beograd: Univerzitet Singidunum. doi:10.15308/Sitcon-2017-132-139

\section{NUTRITION CULTURE IN RELIGIOUS TOURISM}

Apstract:

The goal of this paper is to open the discussion about the need of multicultural approach to food in the field of the needs of religious tourism, as well as to help better understanding of those needs. It should also point out deficiencies regarding the food seen as the nonmaterial cultural heritage. Serbia is a country well known for its hospitality and variety of gastronomic offer. Serbia also requires better accomplishments in the field of religious tourism. The affluence of the material and non-material heritage that can be offered to all the tourists who visit Serbia is its main trump in the time to come.

Keywords:

halal, kosher, religious tourism, religious leaders, culture 